\title{
Oxidation of Low Calorific Value Gases- Applying Optimization Techniques to Combustor Design
}

\author{
Randall S. Gemmen
}

November 1999

U.S. Department of Energy

National Energy Technology Laboratory

Pittsburgh, Pennsylvania

Morgantown, West Virginia

NETL's Customer Service Line: (800) 553-7681

NETL's Homepage: http:/www.netl.doe.gov/ 


\section{Disclaimer}

This report was prepared as an account of work sponsored by an agency of the United States Government. Neither the United States Government nor any agency thereof, nor any of their employees, makes any warranty, express or implied, or assumes any legal liability or responsibility for the accuracy, completeness, or usefulness of any information, apparatus, product, or process disclosed, or represents that its use would not infringe privately owned rights. Reference herein to any specific commercial product, process, or service by trade name, trademark, manufacturer, or otherwise does not necessarily constitute or imply its endorsement, recommendation, or favoring by the United States Government or any agency thereof. The views and opinions of authors expressed herein do not necessarily state or reflect those of the United States Government or any agency thereof.

Available to DOE employees and contractors from the Office of Scientific and Technical Information, P.O. Box 62, 175 Oak Ridge Turnpike, Oak Ridge, TN 37831; prices are available by phone: (423) 576-8401; fax: (423) 576-5725; or e-mail: reports@adonis.osti.gov.

Available to the public from the National Technical Information Service, U.S. Department of Commerce, 5285 Port Royal Road, Springfield, VA 22161; phone orders accepted at (703) 487-4650. 


\section{Acknowledgements}

The author wishes to acknowledge the dedicated efforts of Mr. Edward Robey and Mr. Richard Addis who provided excellent technical support.

This paper was presented at the 1998 International Joint ASME/EPRI Power Generation Conference (IJPGC), Baltimore, MD, August 23-26, 1998. 


\section{Abstract}

The design of an optimal air-staged combustor for the oxidation of a low calorific value gas mixture is presented. The focus is on the residual fuel emitted from the anode of a molten carbonate fuel cell. Both experimental and numerical results are presented. The simplified numerical model considers a series of plug-flow-reactor sections, with the possible addition of a perfectly-stirred reactor. The parameter used for optimization, Z, is the sum of fuel-component molar flow rates leaving a particular combustor section. An optimized air injection profile is one that minimizes $\mathrm{Z}$ for a given combustor length and inlet condition. Since a mathematical proof describing the significance of global interactions remains lacking; the numerical model employs both a "Local" optimization procedure and a "Global" optimization procedure. The sensitivity of $\mathrm{Z}$ to variations in the air injection profile and inlet temperature is also examined. The results show that oxidation of the anode exhaust gas is possible with low pollutant emissions. 


\section{Contents}

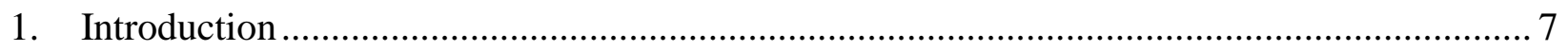

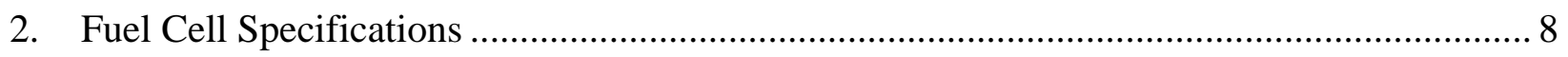

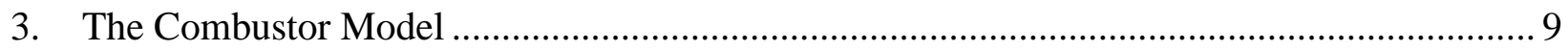

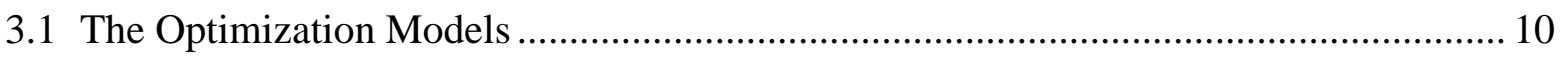

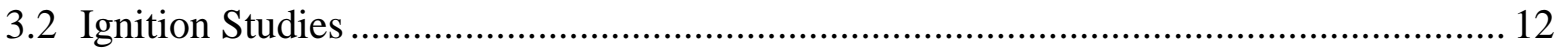

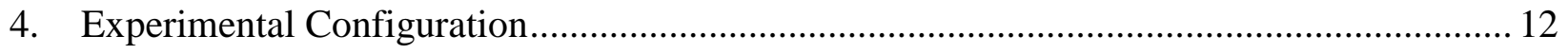

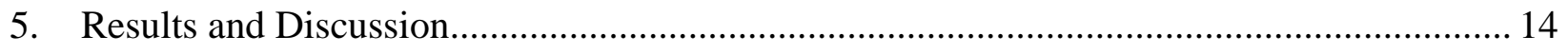

5.1 Global vs. Local Optimized air Injection for PFR Reactors ......................................... 14

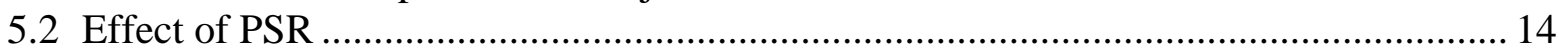

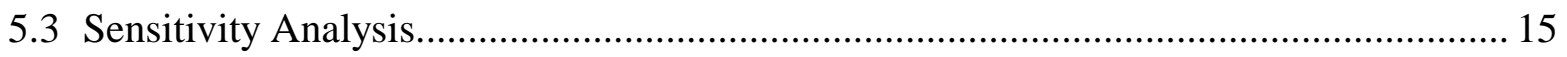

5.4 Ignition Tests and Model Predictions ....................................................................... 16

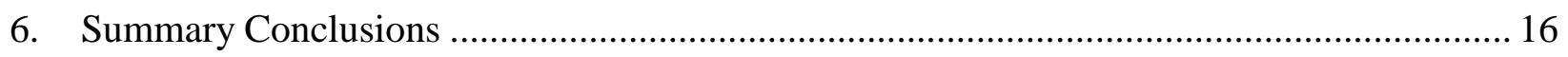

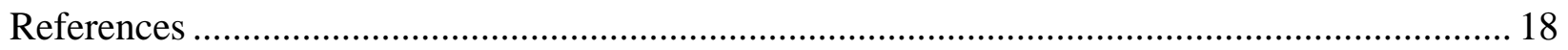

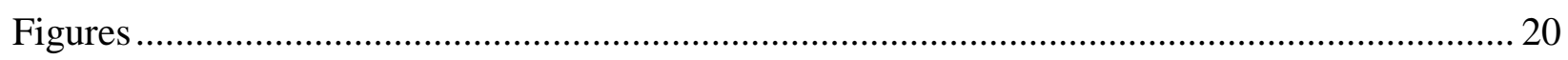




\section{List of Figures}

1: Representative Fuel Cell Flow Configuration.................................................................. 20

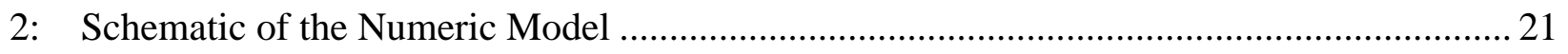

3: Air Injector Cross-Used in the Experiment Employing Counter-Flow Injection.................. 21

4: Gas Generator Simulated Anode Gas Compositions (Dry) ............................................ 22

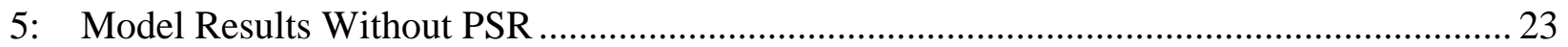

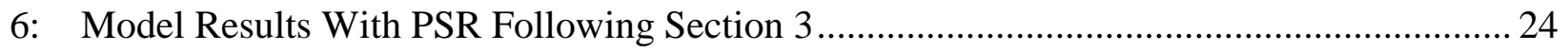

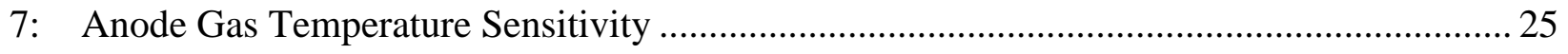

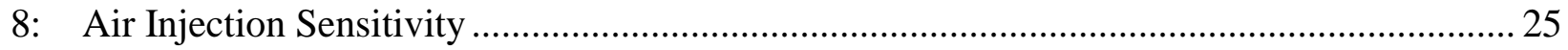

9: Experimental Ignition Data and Model Predictions ................................................. 26 


\section{Introduction}

Unique to many fuel-cell applications is a relatively low fuel energy density anode exhaust gas stream of approximately 1.1 to $1.5 \mathrm{MJ} / \mathrm{m}^{3}$ ( 30 to $40 \mathrm{Btu}$ per standard cubic foot $)^{1}$ that results from the incomplete oxidation of fuel components in the anode section. This residual fuel needs to be oxidized to achieve acceptable pollutant emissions and thermal efficiency. To date, catalytic reactors are usually selected to complete the oxidation of this gas stream. Such systems are expensive and add to the initial cost of the fuel-cell "balance of plant," as well as subsequent operational costs. By improving our understanding of the anode exhaust gas oxidation processes, cheaper and easier to operate combustion systems can be achieved. In addition, current conceptual system designs integrate fuel cells with a gas turbine engine (i.e., the hybrid cycle), (Williams et al. 1995). To achieve optimal performance with projected thermal efficiencies near $75 \%$, these systems will require the oxidation of the anode exhaust gas prior to entering the gas turbine system. Hence, understanding the combustion behavior of these low energy mixtures will aid the future development of these systems as well.

This paper examines the oxidation of an anode-gas stream emitted by a molten carbonate fuel cell through the use of an optimally designed air-staged combustor. While air-staged combustion has been applied in the past to achieve a variety of goals, e.g. Smart and Weber (1989), no known experimental work on optimal air-staged combustion analysis has been reported for fuel energies below $2.2 \mathrm{MJ} / \mathrm{m}^{3}$ (60 Btu per standard cubic foot). In addition, few methodologies have been proposed in the literature for achieving an optimized combustor design. A single air-port combustor (Essenhigh 1974) provides an analytic model that proves an optimal combustor can be achieved through the use of a perfectly-stirred-reactor (PSR) followed by a plug-flow-reactor (PFR), i.e., the Bragg criterion. This result, however, was derived based on simple chemistry, and on the assumption of single-port air injection. Its applicability to other systems needs to be investigated.

This paper presents both a numerical model and an experimental study used for the prediction and assessment of an optimal anode gas oxidizer. Section 2 provides a general description of a fuel cell, and presents the parameter values relevant to this study. The details of the numerical model are presented in Section 3, and the experiment is described in Section 4. Results from both the numerical model and experiment are presented in Section 5, followed by a summary of the main findings in Section 6.

\footnotetext{
${ }^{1}$ Unless otherwise noted, all fuel energy densities are given at their higher heating values.
} 


\section{Fuel Cell Specifications}

Fuel cells convert chemical energy directly into electrical energy through electrolysis (Kordesch and Simader 1996). For the typical molten carbonate fuel cells under consideration, natural gas is mixed with water in a reforming process to create hydrogen and carbon monoxide (Figure 1). Carbonate ions passing through the electrolyte from the cathode react with the hydrogen and carbon monoxide at the surface of the anode at approximately $950 \mathrm{~K}\left(1250{ }^{\circ} \mathrm{F}\right)$. During the reaction, electrons from the carbonate ions are given up to provide a current to drive an external load.

The electrolysis of the hydrogen and carbon monoxide in the anode section is incomplete, causing residual hydrogen and carbon monoxide to exit the anode. Overall chemical-to-electrical conversion efficiencies at the anode are near $75 \%$ for molten carbonate fuel cells, which means that $25 \%$ of the original fuel energy exits as hydrogen and carbon monoxide. Due to the flow of carbonate molecules to the anode $(\sim 3$ carbonate: 1 methane @ 75\% utilization) and the water added for reforming methane, the anode exhaust gas is highly diluted with carbon dioxide and water vapor. There is very little publicized experimental data on fuel cell anode gas composition; however, most models assume near equilibrium concentrations at the anode exhaust temperature. ${ }^{2}$ Therefore, for the current study, a base anode exhaust composition is given as $7.8 \%$ hydrogen and $5.5 \%$ carbon monoxide, with the balance being $48 \%$ carbon dioxide and $39 \%$ water vapor--i.e., near equilibrium at $950 \mathrm{~K}$. This gas mixture has a heating value near $1.5 \mathrm{MJ} / \mathrm{m}^{3}$ (40 Btu per standard cubic foot) higher heating value. Because of this unique gas composition, temperature, and fuel energy density, the best strategy for oxidation is not readily evident from past combustion work.

To achieve optimal system performance, it is mandatory that all of the fuel be oxidized. Likewise, it is important that pressure drops through the system be minimized. Significant engineering design costs are incurred to reduce system pressure drops by as little as one inch of water. Further, to be economically viable, the size of the optimal oxidizer must be kept to a minimum to achieve low capital cost. It is readily apparent that achieving oxidation without a catalyst becomes highly desirable in order to maximize efficiency (lower pressure drop). It is also hoped that by removing the catalyst, lower capital and maintenance costs can be achieved.

Finally, the best combustor will also have an inherent capability to oxidize the fuel; i.e., it will permit the auto-ignition and complete oxidation of the incoming gas. Such a

\footnotetext{
${ }^{2}$ Based on our own independent transient modeling results, however, we anticipate relatively higher concentrations of $\mathrm{CO}$ due to the fact that at temperatures below $1200 \mathrm{~K}$, the gas phase chemical kinetics pushing the system to equilibrium remains relatively slow compared to practical time scales (on the order of minutes). Given the fact that the anode favors $\mathrm{H}_{2}$ electro-chemistry over that of $\mathrm{CO}$, a slight super-equilibrium $\mathrm{CO}$ concentration would appear likely.
} 
combustor will be stable in that, should the fuel cell system have an upset, upon its return to normal conditions the combustor will automatically re-light.

\section{The Combustor Model}

The simplified numerical model employed in this study considers the detailed evolution of the fuel species inside a combustor composed of a series of adiabatic plugflow-reactor sections, and an optional adiabatic perfectly-stirred-reactor inserted anywhere within the series of plug-flow-reactors (Figure 2). Unless otherwise noted, the base configuration used for the model analysis is $128 \mathrm{~mm}$ (5 inch) diameter x $1.8 \mathrm{~m}(5 \mathrm{ft})$ long atmospheric combustor, supplied with an anode gas stream at the base conditions described in Section 2, and flow rate of $9.3 \mathrm{~g} / \mathrm{s}$ (960 scfh). The air for oxidation is supplied at $300 \mathrm{~K}$ and atmospheric pressure.

This model is an extension of the work reported by Gemmen (1996) which had simplified chemistry. For plug-flow-reaction, the system is considered to be onedimensional and non-diffusive. For perfectly-stirred reaction, the system is considered to be zero-dimensional, or fully mixed. For this work, 11 plug-flow-reactor sections are used. At the inlet to each combustor section some quantity of air is injected and rapidly mixed with the incoming gas from the previous combustor section. The mixture then undergoes reaction according to the type of combustion (plug-flow or perfectly-stirred) until the mixture leaves the combustor section. The simulation employed the reaction set from Kim et al. (1991) and thermodynamic data from the Chemkin database (Kee at al. 1989). Because of the parabolic mathematical nature of the proposed model, the solution of the problem is achieved by starting at the first combustor, and sequentially assessing the solution for each downstream combustor. The solution of each plug-flow-reactor was performed by the LSODE routine described by Radhakrishnan and Hindmarsh (1993). The solution of the perfectly-stirred reactor was solved by the PSR routine described by Glarborg et al. (1990). The numerical routines were written in 32-bit C++, and executed on a $233 \mathrm{MHz}$ PC. The model was validated by comparisons with Mulholland et al. (1992) and direct comparisons with other Chemkin model results for problems representative of the current study.

Two types of calculations were performed using the model. One calculation determined the optimal air injection profile for a given length combustor and fuel inlet condition (temperature, species, and mole flux), both with and without a PSR. For this calculation, two different optimization methods are examined. Another calculation predicted the minimum fuel energy density required at the inlet in order to achieve autoignition for a given fuel inlet condition, air injection profile, and combustor length. Results from this calculation were compared to experimental auto-ignition data. Both calculations are described in detail in the following sections.

In spite of the fact that diffusional processes are absent within the model's PFR sections, the present model should be suitable for these two studies, since we desire the 
prediction of a self-ignitable combustor. For such practical results where the greatest importance lies in the pre-ignition processes, the role of diffusion transport (whether molecular or turbulent) in the reaction processes leading up to ignition is not significant (Mulholland et al. 1992). It is not until the species and temperature gradients become very large near the flame-front that diffusion becomes significant. However, by then the model has sufficiently predicted the ignition event--at least for the practical purposes desired in this study. In general, however, diffusion can play a significant role in making a combustor suitable for a given application as it can support the existence of hysteresis. With hysteresis, the combustion of fuel, once lit within the combustor, is found to remain stable in spite of slight upsets in inlet conditions. This type of stability information cannot be predicted with the current model.

\subsection{The Optimization Models}

In order to obtain the shortest combustor with a high fuel conversion efficiency, we can expect that the reaction rate of the anode gas mixture needs to be maximized in some way--whether it can be maximized locally along the combustor or requires global optimization remains to be determined. In simple terms, the modified Arrhenius rate expression that governs fuel oxidation chemistry can be written as

$$
\mathrm{RR}=[\mathrm{F}][\mathrm{O}] \mathrm{A} \mathrm{T}^{\mathrm{n}} \exp [-\mathrm{E} / \mathrm{RT}]
$$

where $\mathrm{RR}$ is the reaction rate parameter, $[\mathrm{F}]$ is the fuel component concentration, $[\mathrm{O}]$ is the oxidizer concentration, $\mathrm{A}$ is the Arrhenius rate coefficient, $\mathrm{T}$ is absolute temperature, $\mathrm{n}$ is the pre-exponential, $\mathrm{E}$ is the reaction energy, and $\mathrm{R}$ is the universal gas constant. As is evident from this equation, to achieve locally the highest reaction rate $R R$ in a hot fuel mixture, there will be a trade-off between increasing the concentration of oxidizer [O] and slowing down the molecular kinetics $\left(\mathrm{AT}^{\mathrm{n}} \exp [-\mathrm{E} / \mathrm{RT}]\right)$, as relatively cool ambient air is added. Hence, a search for the optimal air injection to any section needs to be made.

Two different optimization methods have been examined in this study ${ }^{3}$. In both methods, the optimization parameter is defined as the summed molecular flow rates of hydrogen and carbon monoxide leaving a particular combustor section. It is assumed that the best combustor design will have an air injection profile along the combustor that

\footnotetext{
${ }^{3}$ There are many methods described in the literature that efficiently determine the optimal solution to a given problem. One method that is frequently suggested to apply to the current problem is called Dynamic Modeling (Stoecker 1989). Dynamic Modeling is a formal method for determining the optimal configuration of staged systems. However, because this method works the problem in reverse (from exhaust to inlet), it necessarily assumes that the system is reversible. This is not the case for the current problem where multiple pathways (in terms of concentration and temperature history) can lead to the same final (exhaust) solution (i.e., ultimately equilibrium temperature and concentrations.)
} 
minimizes this parameter (i.e., maximizes the overall reaction rate through one (or more) combustor section[s]). The most general of the two methods, referred to as the Global model, accounts for the fact that the performance of upstream combustor sections affect downstream combustor sections. The other method, referred to as the Local method, ignores this effect, but it can produce an optimized solution nearly 100 times faster than the Global method. While the Local method is not as general, its results compare well with the Global model for the current experimental application where only plug-flow reactors are used.

The Local procedure assumes that the optimal air injection profile for the overall combustion system can be found by determining the air injection at each individual section, "i", that produces the lowest total flow rate of fuel components, $\mathrm{z}_{\mathrm{i}}$, exiting that section. Hence, the solution procedure is to move sequentially downstream through the combustion system, starting at the inlet, and locally determine the optimal air injection flow rate. Because this procedure only passes through all combustor sections once, it is very efficient and offers fast solutions. The validity of the assumption that the optimal air injection profile for the overall system can be obtained by such a local optimization procedure is examined in Section 5.

In the Global model, the optimization parameter, Z, is defined as the summed molecular flow rates of hydrogen and carbon monoxide leaving the last combustor section. It is assumed that the best combustor design will have an air injection profile along the combustor that minimizes this parameter. The assessment of $\mathrm{Z}$ for a given air profile considers the downstream integration across all combustor sections; hence, the Global procedure considers the possibility that the optimal air injection at section "i" may require non-optimized (in the Local sense) air injection at combustor sections upstream of "i." Since at this time there is no mathematical proof available that shows how the search domain might be constrained (and, hence, how to efficiently avoid certain profile domains) a consideration of all possible profiles is required. Given the aforementioned requirements and limits on understanding, simple logic suggests that a random examination of all possible air injection profiles be performed to ensure a truly optimized solution.

A limited form of such a search routine is now described. The global procedure uses a directed search method that begins with a user defined air injection profile. The search proceeds by separately considering each combustor section using two different perturbation procedures. The first procedure assumes that the total air injected is fixed at the current value. During the analysis of each section, the amount of air injected at the section is increased a small amount from its prior determined (current optimal) value. Because of the constraint on the total injected air, the amount of air injected in all other combustor sections is decreased a small amount from their prior determined optimal profile values. The decrease can happen uniformly over all other combustor sections, or can occur completely over just one combustor section at a time; however, no section can have negative air injection values. Both techniques are tried separately and the entire combustion system is analyzed for the new flow conditions. If an improvement to the 
optimization parameter, Z, is discovered, then the new profile is saved, from which further adjustments are also attempted to determine other improved air injection profiles. The second perturbation procedure does not constrain the total air to be fixed. Instead, it simply adds or subtracts a small amount of air from a section to test if an improved profile results. The entire procedure is terminated once the adjustments (less than $0.1 \%$ of the current total air flow value) no longer show any improved profile. The results of this method are compared to the Local method in Section 5.

\subsection{Ignition Studies}

The model was used to predict the inlet conditions at which auto-ignition could occur for a given anode gas mole flux, air injection temperature, airflow profile, and combustor length. There are a variety of definitions for "ignition" within the literature: "turning points" for PSR calculations, maximum slope or point-of-inflection for PFR calculations, etc, (Mulholland et al. 1992). For the practical purposes of this work, ignition is defined to be sufficiently achieved if at least $90 \%$ of the fuel has been oxidized prior to leaving the combustor. The fact that less than $10 \%$ of the fuel could possibly remain unoxidized for the prediction is immaterial to this ignition study. The only objective is to assess whether sufficient combustion was possible, and not whether the given combustor provides optimal chemical conversion. In practice, it is found that once at least half the inlet fuel energy is reacted, a sufficient temperature rise is achieved $(T>1150 \mathrm{~K})$ such that any remaining oxidation proceeds immediately, subject only to the availability of oxidant.

This ignition algorithm was used to generate a map of conditions under which ignition occurs, and the results compared to experimental data. For this mapping, the model employed the same operating conditions (species composition, temperature, flow rates, etc.) as that used in the experiment. For a given condition, the point of ignition was determined by continually changing the inlet $\mathrm{H}_{2}$ and $\mathrm{CO}$ mole fractions (by the same factor) and searching for the minimum total inlet fuel energy density needed to achieve ignition at a given inlet temperature.

\section{Experimental Configuration}

The experiment investigated the ignition behavior for a molten-carbonate anode exhaust gas mixture and the emission levels produced using a short, air-staged combustor. Because of the flow rates used, and the relatively high temperatures needed $(>1000 \mathrm{~K}$ or $1350{ }^{\circ} \mathrm{F}$ ) a gas generator burning a mixture of natural gas, oxygen, and carbon dioxide was used to simulate the anode gas emitted from a fuel-cell. Liquid oxygen and liquid carbon dioxide dewars supplied oxygen and carbon dioxide gas with flow rates of 4.03 $\mathrm{g} / \mathrm{s}(386 \mathrm{scfh})$ and $4.13 \mathrm{~g} / \mathrm{s}(288 \mathrm{scfh})$, respectively. Natural gas at a nominal flow of 1.18 $\mathrm{g} / \mathrm{s}(225 \mathrm{scfh})$ was mixed with the oxygen and carbon dioxide streams and burned in the combustor. A $25 \mathrm{~mm}$ (1 inch) thick aluminum-oxide refractory material was used to protect the metal walls of the combustor. The hot combustion gases were cooled via 
internal and external water coils to reflect that $75 \%$ of the fuel energy in a fuel cell is removed as electric power. The cooled gases at $920 \mathrm{~K}$ to $1000 \mathrm{~K}\left(1200{ }^{\circ} \mathrm{F}\right.$ to $\left.1350{ }^{\circ} \mathrm{F}\right)$ entered the $128 \mathrm{~mm}$ diameter x $1.5 \mathrm{~m}$ long development combustor, where air at $560 \mathrm{~K}$ $\left(550{ }^{\circ} \mathrm{F}\right)$ was injected at 11 evenly spaced locations along its axis. The air injection occurred through a cross-member having two rows of $4,0.66 \mathrm{~mm}(0.026$ in.) diameter holes equally spaced along each of the legs (Figure 3). The air from each hole was injected at 45 degrees from the upstream axial direction (counter-flow air injection) in order to mix the air and fuel streams as quickly as possible. A simple two step air injection profile was selected for these studies, having $28 \%$ of the total air evenly injected through the first 5 injectors with the balance evenly injected through the final 6 injectors. Three different total amounts of air were tested to show its effect on the ignition process: $3.4 \mathrm{~g} / \mathrm{s}$ (350 scfh), $4.4 \mathrm{~g} / \mathrm{s}(450 \mathrm{scfh})$ and $5.3 \mathrm{~g} / \mathrm{s}(550 \mathrm{scfh})$. The injected air completed the oxidation of the residual fuel energy, and the exhaust products were removed from the building through a $8 \mathrm{~m}$ ( $25 \mathrm{foot})$ long stack after being diluted by up to $97 \mathrm{~g} / \mathrm{s}$ (10000 scfh) of air.

The experimental evaluation for the ignition curves was accomplished by achieving even temperatures along the axis of the combustor and then slowly increasing the amount of excess fuel to the gas generator until ignition was detected by a series of thermocouples located along the centerline of the combustor. This procedure was performed for a range of inlet (anode) gas temperatures for each of the three air flow rates studied.

A gas analysis system was employed in the experiment to measure the concentrations of molecular hydrogen, carbon monoxide, carbon dioxide, oxygen, nitrogen oxides, methane, and non-methane species. The gas was continuously sampled using heated stainless steel tubing until the sample reached a conditioning unit where the water vapor was removed. The dry sample was then analyzed by the on-line gas analyzers: $\mathrm{H}_{2}$ (gas chromatograph), $\mathrm{CO}$ (NDIR), $\mathrm{CO}_{2}$ (NDIR), NOx (chemiluminescense), $\mathrm{O}_{2}$ (zirconium oxide), and fuel (flame ionization). Due to the wide range of CO (10 ppm to 20\%), three different analyzers for $\mathrm{CO}$ were used. Gas was sampled separately upstream and downstream of the development combustor to evaluate combustor performance.

Figure 4 shows the mole fractions (dry basis) of carbon dioxide, hydrogen and carbon monoxide that are produced by the gas generator for various fuel energy densities as controlled by the excess fuel delivered to the gas generator. As can be seen, the relative concentrations of carbon monoxide and hydrogen are different from the near equilibrium anode exhaust values described in Section 2.

In particular, the experimental data has higher carbon monoxide and less hydrogen. ${ }^{4}$

\footnotetext{
${ }^{4}$ Although the gas generator produces compositions different from what is normally assumed for fuel cell modeling, the difference may be beneficial given the relatively higher CO anticipated in the actual system. See footnote in Section 2.
} 
This discrepancy was determined (by a separate detailed chemistry model study) to be due to the quenching of the chemistry which occurs once the gas temperature is reduced below about 1500 to $1600 \mathrm{~K}$ (2200 to $2400{ }^{\circ} \mathrm{F}$ ). Based on prior work showing that higher proportions of carbon monoxide causes slower overall reaction rates (Chomiak et al. 1989), it is expected that the results obtained from the current work will provide a conservative-length estimate for the optimal combustor needed in a fuel cell application. For example, the burning velocity data of Chomiak et al. (1989) shows that the flame speed of the fuel-cell gas may be approximately two times greater than the flame speed of the gas used in the experiment. Hence, a smaller combustor for the fuel cell is likely.

\section{Results and Discussion}

\subsection{Global vs. Local Optimized Air Injection for PFR Reactors}

Figure 5 shows the results predicted by the Local model for the base configuration described in Section 3, and where only PFR reactors are considered. The air injection results are shown normalized by the total injected air predicted by the search routine $(7.4$ $\mathrm{g} / \mathrm{s}$ ), and the fuel by the inlet fuel flow rate. As can be seen, the optimal profile requires a small injection at Injector 1 . Injector 2 shows significantly less air injection, followed by an increased injection at Injector 3. Injectors $4 \& 5$ show decreasing air injection, followed by increasing injection at Injectors 6,7 and 8. While the fuel remaining at the entrance to section 9 is already near ppm levels, more air is injected at Injectors 9, 10 and 11 to produce a total fuel flow exiting the combustor of $2.5 \mathrm{E}-7 \mathrm{~mole} / \mathrm{s}$. Throughout the process, the temperature slowly rises, and the concentrations of $\mathrm{H}_{2}$ and $\mathrm{CO}$ decrease--note for future discussion, less than $1 \mathrm{ppm}$ of fuel components remain after $1.6 \mathrm{~m}$.

Figure 5 also shows the results predicted by the Global model for the same conditions as used in the Local model. The Global model was initialized using the results from the Local model presented above. The Global search results determined a need for $4 \%$ more air than that predicted by the Local model. The results also showed a 5\% reduction in the exhaust fuel compared to the Local model. In short, except for the air injection profiles, the Global results come fairly close to those of the Local model (air values at Injectors 2, 4, 7 and 11 are significantly different). This result is similar to that produced by the relatively simple and independent chemistry model reported by Gemmen (1996). While a separate study that resolves the concern of relative vs. absolute minimums must still be performed, these results suggest that using the Local procedure is satisfactory for these fuel cell studies. The many other profiles examined during the Global procedure need not be considered, except for achieving slightly more refined emission predictions.

\subsection{Effect of PSR}

The effect of adding a PSR (200 mm diameter $\mathrm{x} 300 \mathrm{~mm}$ length which has a length/diameter ratio representative of a typical dump combustor) to the previous system (with PFR sections now of total length $1.5 \mathrm{~m}$, thereby preserving an overall system length 
of $1.8 \mathrm{~m}$ ) was investigated by separately considering all the combinations of PFR \& PSR sequences. Both the Local and Global optimization routines were used (the Global cases again being initialized from the Local results). The best location for a PSR that caused the combustion to occur earliest was following section three for the Local cases, while that for the Global cases was at the inlet. The results for the PSR following section three will be presented first.

The Local and Global results for the PSR following section three are shown in Figure 6. The Local predictions show 1 ppm concentrations being achieved by $1.55 \mathrm{~m}$ and a fuel flow rate of 2.1E-7 mole/s at the combustor exit. These are minor reductions as compared to the results without a PSR presented in Fig. 5. Comparing the Local and Global predictions in Figure 6 now, however, show significantly different results. In particular, the Global air injection profile shows more air at the inlet and relatively fewer bumps. Also, 24\% more air was needed for the Global prediction, which resulted in $65 \%$ less fuel flow at the exit as compared to the Local results. In addition, the Global predictions now show 1 ppm concentrations being achieved by $1.2 \mathrm{~m}$. It is apparent that chemical processes within a PFR \& PSR combined system result in significant Global interactions. To better point to the main contributing factor (is it the fact that a PSR exists in combination with a PFR system, or is it that PSR combustors themselves fundamentally produce Global influence), a separate study of 11 series of PSR combustors is required. This issue is left for a later study.

While the best PSR location determined via the Local model was following the third PFR, the Global model showed the best PSR location to be at the inlet. Interestingly, this is in agreement with the analytical work of Essenhigh (1974) for relatively simple combustor designs, but which could not account for any Global interactions. The Global prediction with the PSR at the inlet showed only slightly different air injection behavior as that reported in Figure 6. Also, only 6\% more air was needed. Yet it resulted in 36\% less fuel flow at the exit and 1 ppm concentrations now being achieved within only $0.9 \mathrm{~m}$.

In spite of the seemingly good benefit achieved by adding a PSR (combustion occurring earlier), the cost of doing so was equivalent to adding a $0.7 \mathrm{~m}$ (27.6 in.) long PFR section to the existing 11 PFRs (using volume equivalence and equal diameters). This would make the total length of the combustor $2.2 \mathrm{~m}$ (86 in.) long instead of $1.8 \mathrm{~m}$ long ( $1.5 \mathrm{~m}$ of existing PFR sections $+0.7 \mathrm{~m}$ due to the PSR equivalent PFR.) This significantly reduces the practical benefit of adding a PSR for the current problem. Having arrived at this cost/benefit result, we have not pursued the PSR configuration in our experimental work. Future work will examine this conclusion more closely to determine if other PSR geometries perform better under multi-airstaged injection.

\subsection{Sensitivity Analysis}

Figures 7 and 8 show the sensitivity of the exhaust fuel flow rate $(Z)$ to inlet temperature and air injection, respectively, for the PFR system analyzed in Section 5.1. For these analyses, the Global optimized solution was perturbed (in either inlet 
temperature or airflow rate) with all other parameters held fixed, and the performance of the combustor evaluated. As shown in Figure 7, even small decreases in anode exhaust temperature can significantly degrade the performance of this combustion system. Such model results reflect flameout conditions common to most combustion systems. It is apparent that, to reliably perform the oxidation over the $1.8 \mathrm{~m}$ length combustor, the inlet temperature needs to be maintained above $950 \mathrm{~K}$. If lower inlet temperatures are used, a new (longer) combustor design would be required. For the air injection sensitivity results shown in Figure 8, it is seen that relatively weak effects occur when going richer. For leaner conditions, the sensitivity is high for air ports \#3 to \#7 when at least $8 \%$ more air is injected. For changes less than 2-4\%, only injector \#4 shows a significant effect.

\subsection{Ignition Tests and Model Predictions}

Figure 9 shows the results from the experimental tests on the ignition behavior of the simulated anode gas. The figure shows that for a given anode gas temperature and total air flow rate, a minimum fuel energy density is required before the mixture will ignite within the $1.5 \mathrm{~m}$ long combustor. Also shown are the model predictions when analyzed using the same conditions (air profile, total air, air temperature, and simulated anode gas composition, etc.) as employed in the experiment. The model results follow the experimental data remarkably well. While the data is somewhat "noisy," the general trend of increasing fuel needed for ignition with increasing air is also evident. A statistical analysis shows that there is only a 5\% probability that the changes seen with airflow rate are due to random variation.

For the conditions tested, analyzer data showed that at least $350 \mathrm{scfh}$ air flow at $40 \%$ excess air was required to reduce CO levels below 1 ppmv (wet @ 15\% O2). NOx increased slightly with excess air, but was always less than about 4 ppmv (wet @ 15\% O2).

\section{Summary and Conclusions}

The performance of a post-anode gas phase reactor has been examined via numerical modeling and experimental testing. The model employed a Local (for fast predictions) and Global (for improved predictions) optimization routines. Representative test cases were modeled with and without a PSR included in a series of PFRs. The experiment was configured as a series of 11 PFRs, with inlet conditions that approximated those found at the anode exit of a molten-carbonate fuel cell.

Model results show that Local and Global profile predictions are similar when only PFR reactors are present. This result is fortunate as it allows the use of the efficient Local routine for finding optimal air profiles. For the pure PFR system studied, the optimal air injection profile requires a small addition of air at the inlet, followed by a short "cooking time," followed by a relatively large injection of air to complete the oxidation. The model results also showed that the sensitivity of the air injection ports due to departures 
from their optimal values is greatest for injectors \#3 to \#7, and only when 2-4\% more air is injected.

When a PSR is included in the series of PFRs, the model shows significantly different air profile predictions between the Local and Global routines. This result is unfortunate as it indicates that, to achieve true optimization with a PSR combustion system, very time consuming search-and-find procedures are required until tools are derived that provide knowledge of what air profile domains can be avoided. Finally, for the PSR selected, the oxidation could occur in a much smaller length. However, in spite of the improved performance achieved by adding a PSR, a preliminary cost/benefit assessment tentatively suggests that only PFRs need be considered for the fuel cell oxidizer. More work is needed to determine if other PSR geometries provide improved results.

Experimental results show that the complete oxidation of the anode gas can be achieved in a distance of less than $1.5 \mathrm{~m}(5 \mathrm{ft})$. These results can be achieved with very low CO $(<1 \mathrm{ppm})$ and NOx $(<10 \mathrm{ppm})$ emission levels. A comparison of model predictions to the experimental results show the model to reliably predict the ignition behavior of the experimental gas mixture. 


\section{References}

Chomiak, J., J.P. Longwell, and A.F. Sarofim. 1989. Combustion of Low Calorific Value Gases; Problems and Prospects. Progress in Energy and Combustion Science. 15:109-129.

Essenhigh, R.H. 1974. "An Introduction to Stirred Reactor Theory Applied to Design of Combustion Chambers." Combustion Technology: Some Modern Developments, 373397. Ed. Howard B. Palmer and J.M. Beer. New York: Academic Press.

Gemmen, R.S. 1996. Optimized Air Staged Injection of the Oxidation of Low Calorific Value Gases. Presented at the 1996 Eastern States Fall Technical Meeting, Hilton Head, SC, Dec. 9-11.

Glarborg, P., R.J. Kee, J.F. Grcar, and J.A. Miller. 1990. PSR: A Fortran Program for Modeling Well-Stirred Reactors. Sandia National Laboratory Report, SAND86-8209.

Kee, R.J., F.M. Rupley, and J.A. Miller. 1989. Chemkin-II: A Fortran Chemical Kinetics Package for the Analysis of Gas-Phase Chemical Kinetics. Sandia National Laboratory Report, SAND89-8009.

Kim, T.J., R.A. Yetter, and F. L. Dryer. 1994. New Results on Moist CO Oxidation: High Pressure, High Temperature Experiments and Comprehensive Kinetic Modeling, Twenty-Fifth Symposium (International) on Combustion, The Combustion Institute, pp. 759-766.

Kordesch, K. and G. Simader. 1996. Fuel Cells and Their Applications. VCH Verlagsgesellschaft, New York.

Miller, J.A. and C.T. Bowman. 1989. Mechanism and Modeling of Nitrogen Chemistry in Combustion. Progress in Energy and Combustion Science. 15:287-338.

Mulholland, J.A., A.F. Sarofim, and J.M. Beer. 1992. On the Derivation of Global Ignition Kinetics from a Detailed Mechanism for Simple Hydrocarbon Oxidation. Comb. Sci. and Tech. 87:139-156.

Radhakrishnan, K. and A.C. Hindmarsh. 1993. Description and Use of LSODE, the Livermore Solver for Ordinary Differential Equations. NASA Reference Publication 1327.

Smart J. P. and Weber R. 1989. Reduction of NOx and Optimisation of Burnout With an Aerodynamically Air-Staged Burner and an Air-Staged Precombustor Burner. J. Inst. Energy. 62:237-245. 
Stoecker, W.F. 1989. Design of Thermal Systems. Third ed. New York: McGraw-Hill, Inc.

Williams, M.C., P.L. Micheli, and E.L. Parsons, Jr. 1995. Engineering a 70-Percent Efficient, Indirect-Fired Fuel-Cell Bottomed Turbine Cycle. Proceedings of the Fuel Cells 1995 Review Meeting. August 1995, ed. T.J. George, DOE/METC-95/1020. 


\section{Figures}

\section{Carbonate Fuel Cell}

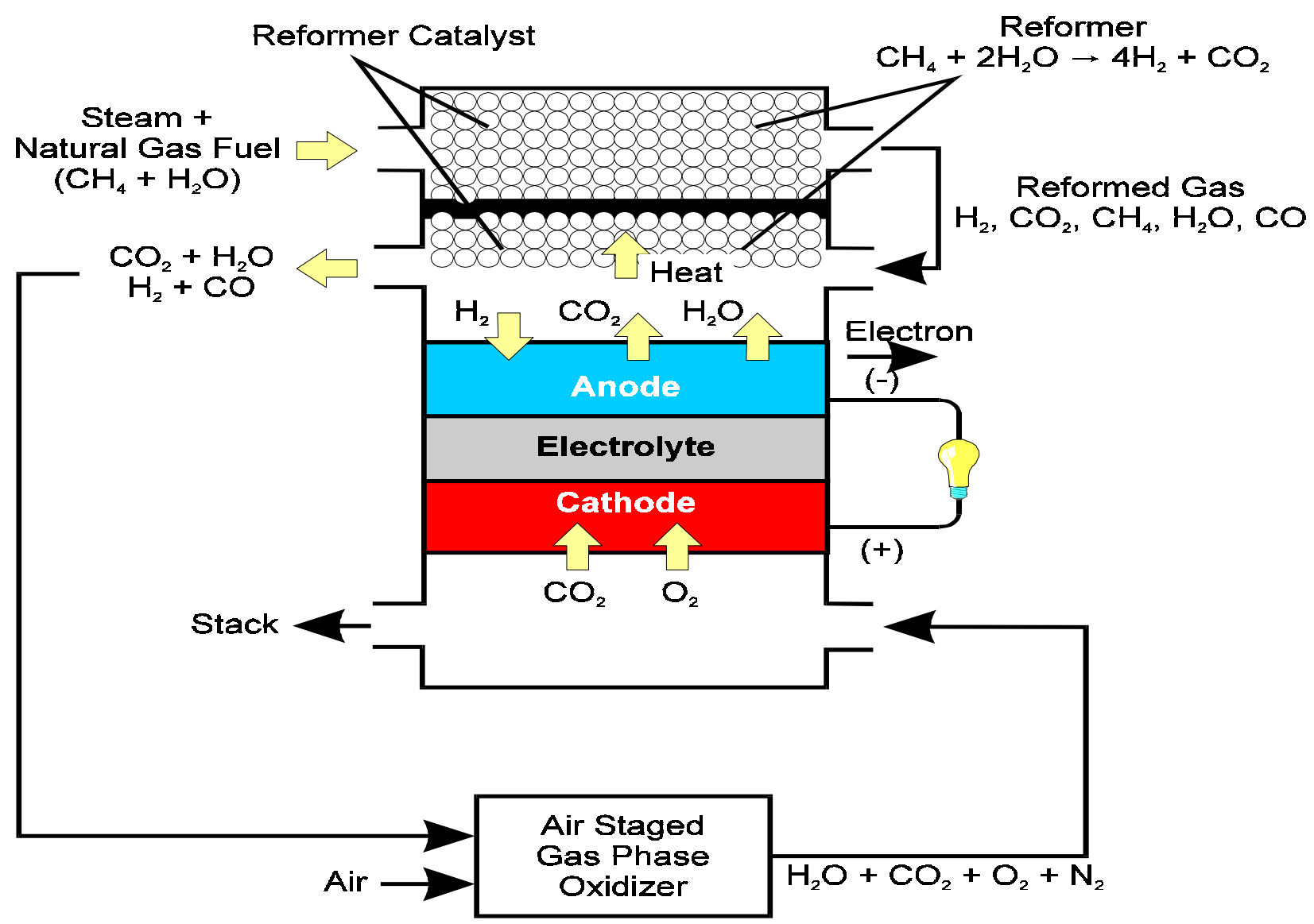

Source: EPRI Technical Brief, RP3058-01

Figure 1. Representative Fuel Cell Flow Configuration 


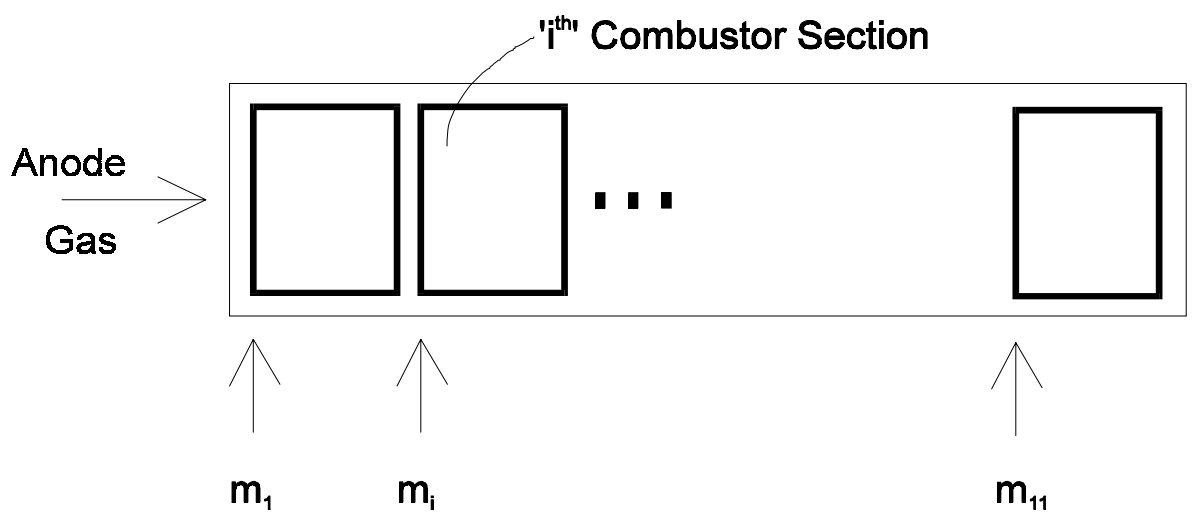

Figure 2. Schematic of Numeric Model

(where $\mathrm{m}_{\mathrm{i}}$ denotes the mass rate of air injected at section "I")

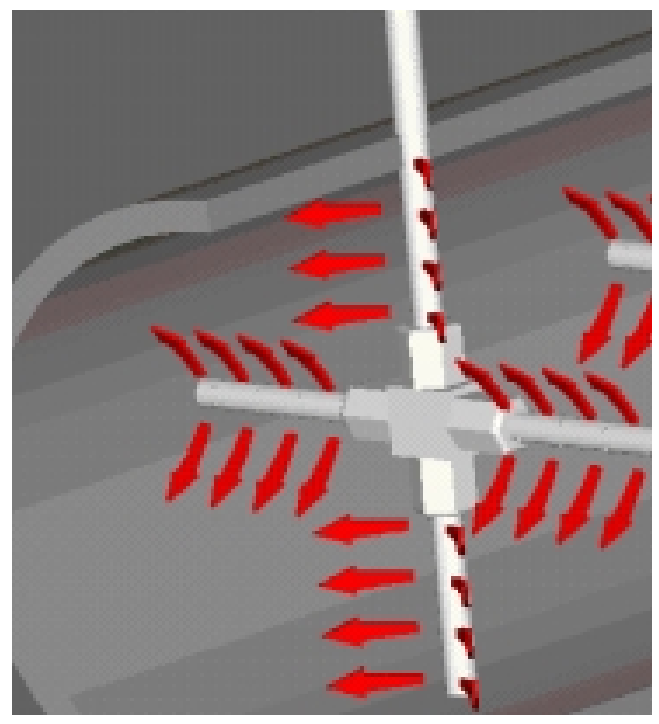

Figure 3. Air Injector Cross-Used in the Experiment Employing Counter-Flow Injection 


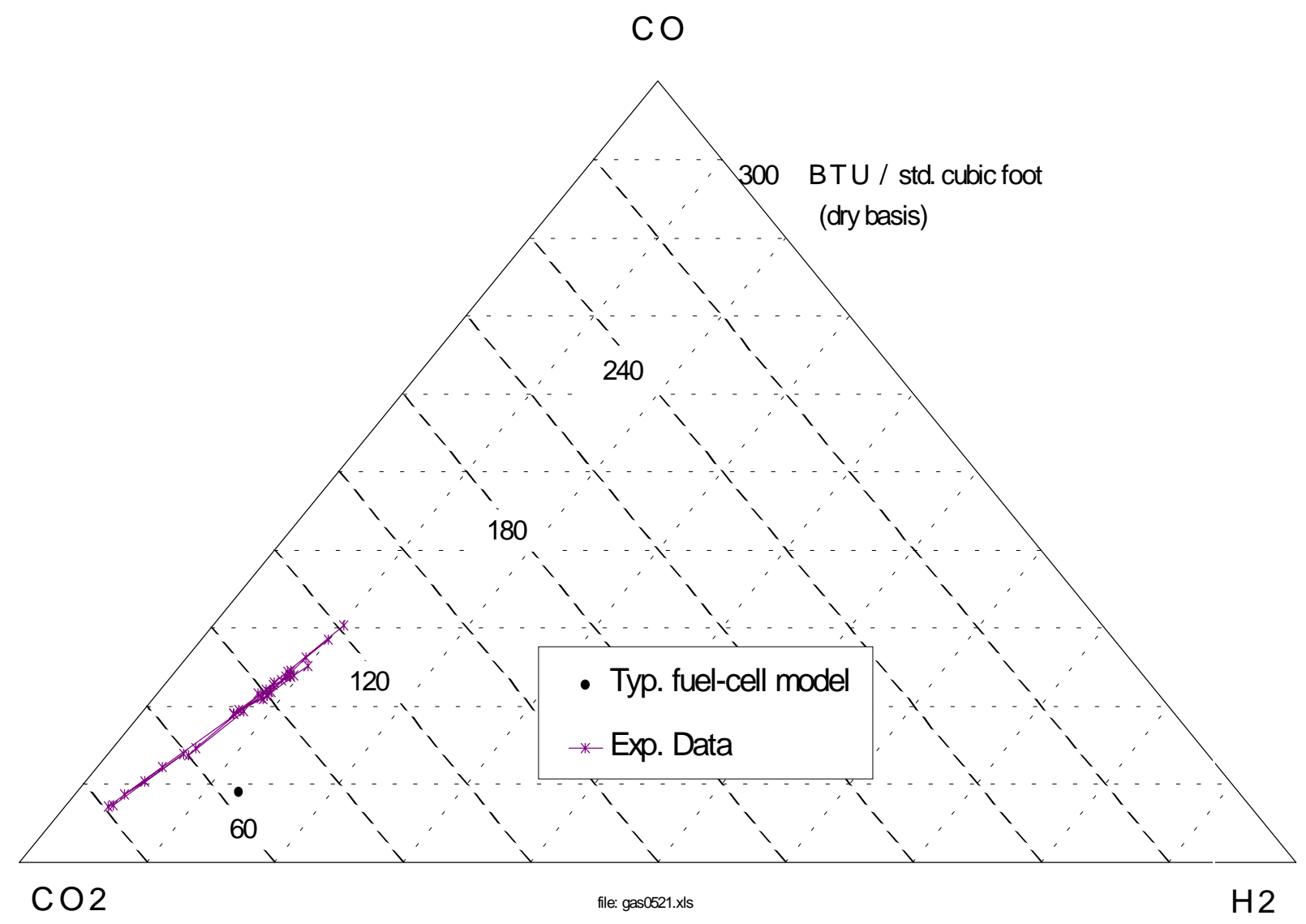

Figure 4. Gas Generator Simulated Anode Gas Compositions (Dry) 


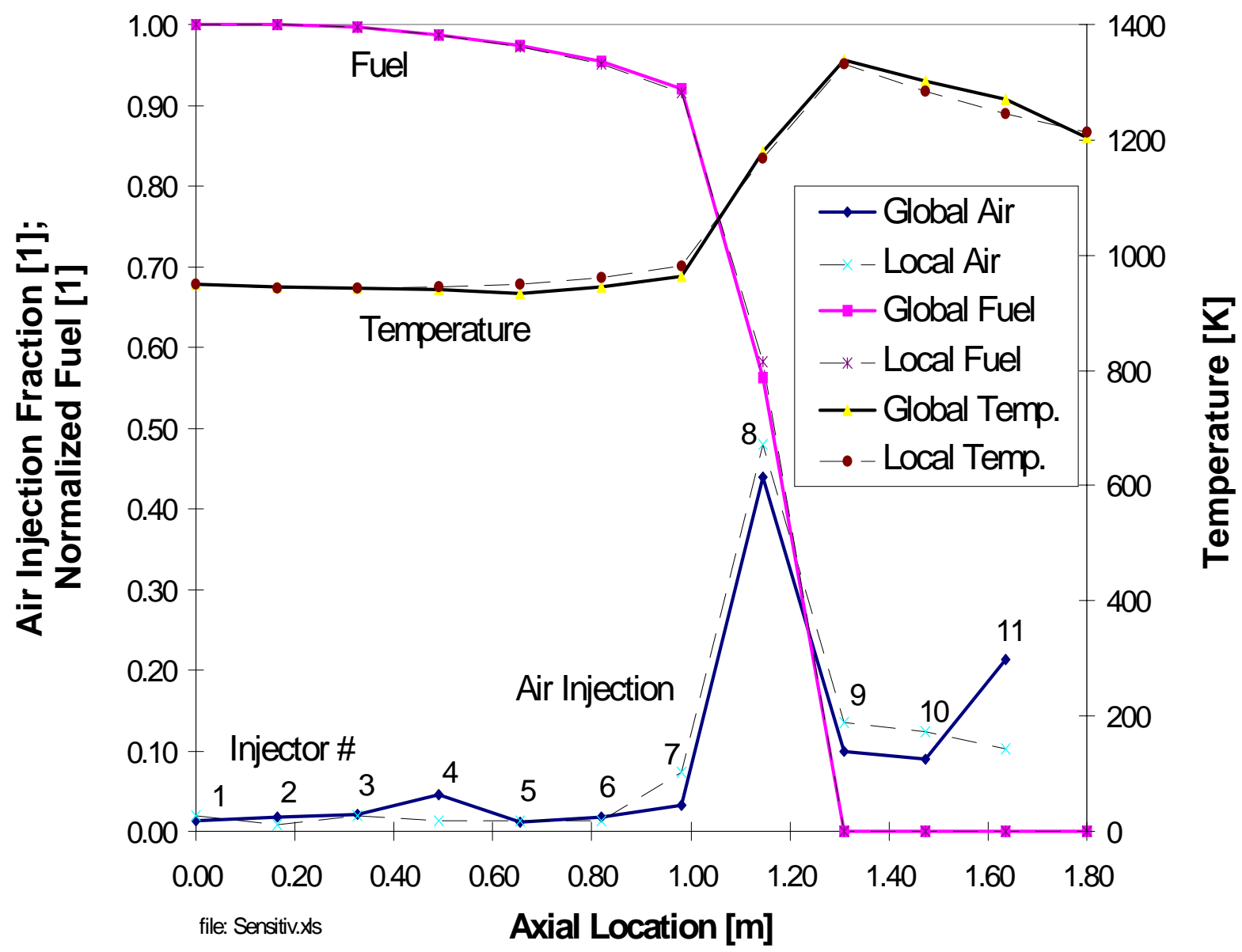

Figure 5. Model Results Without PSR 


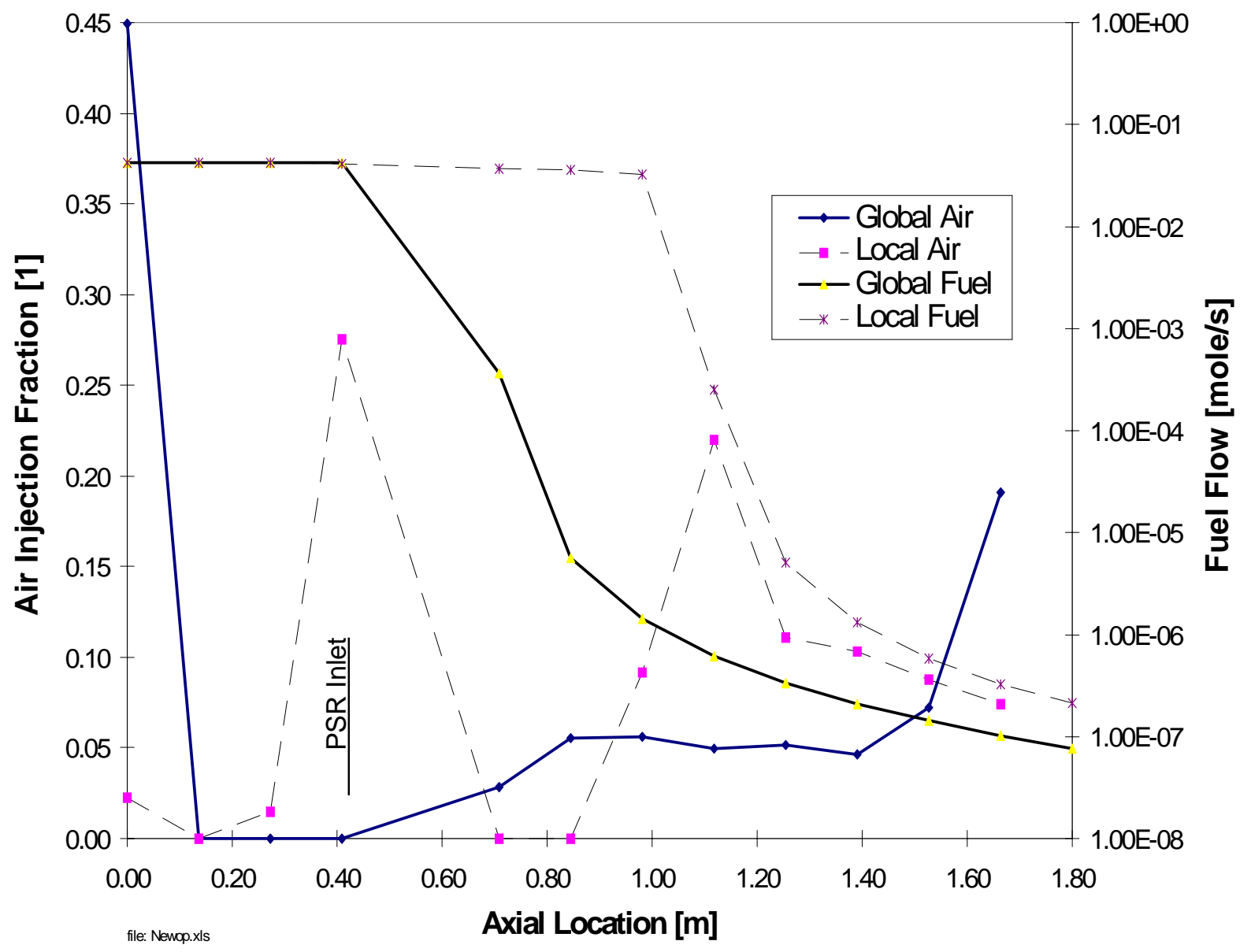

Figure 6. Model Results with PSR Following Section 3 


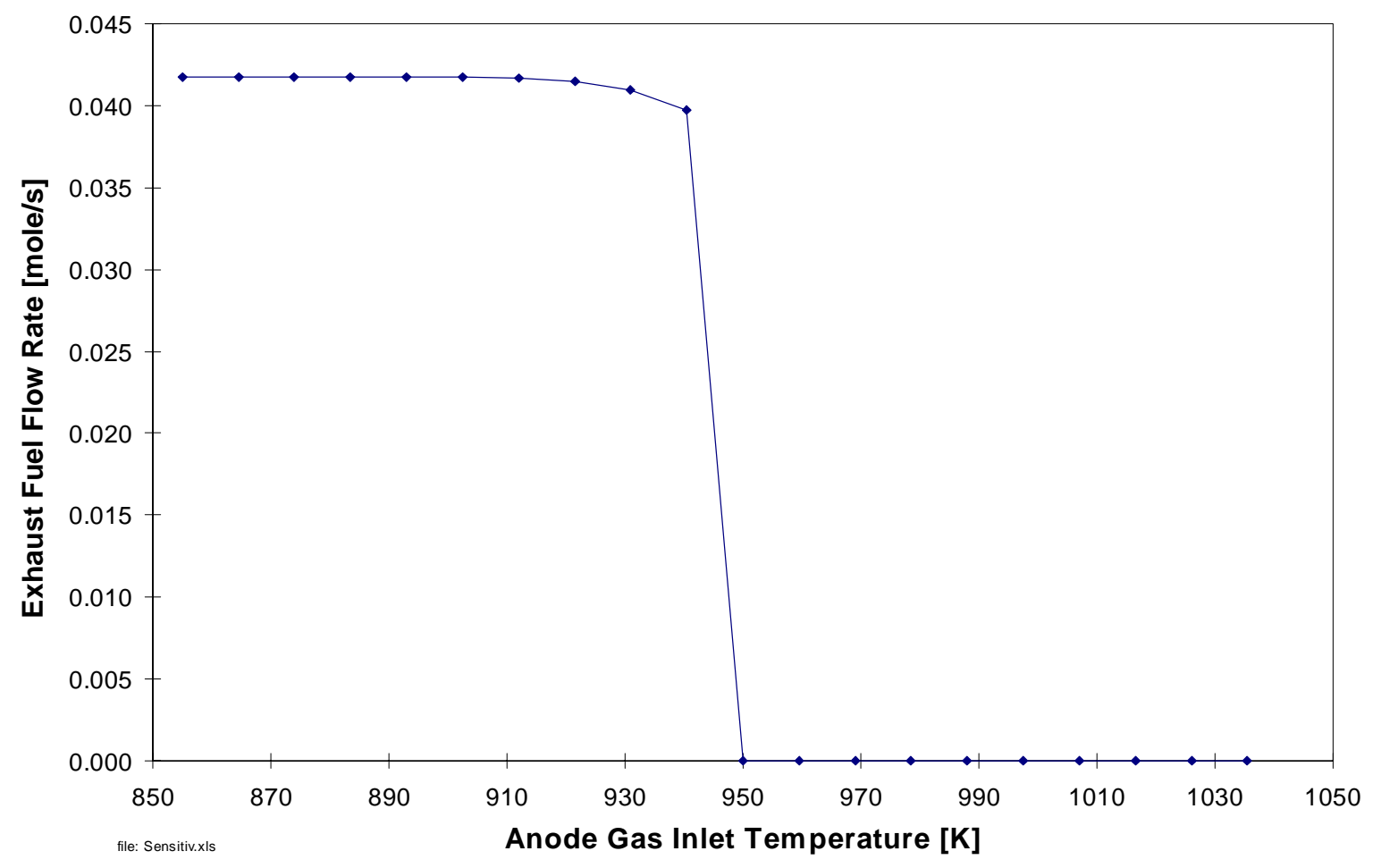

Figure 7. Anode Gas Temperature Sensitivity

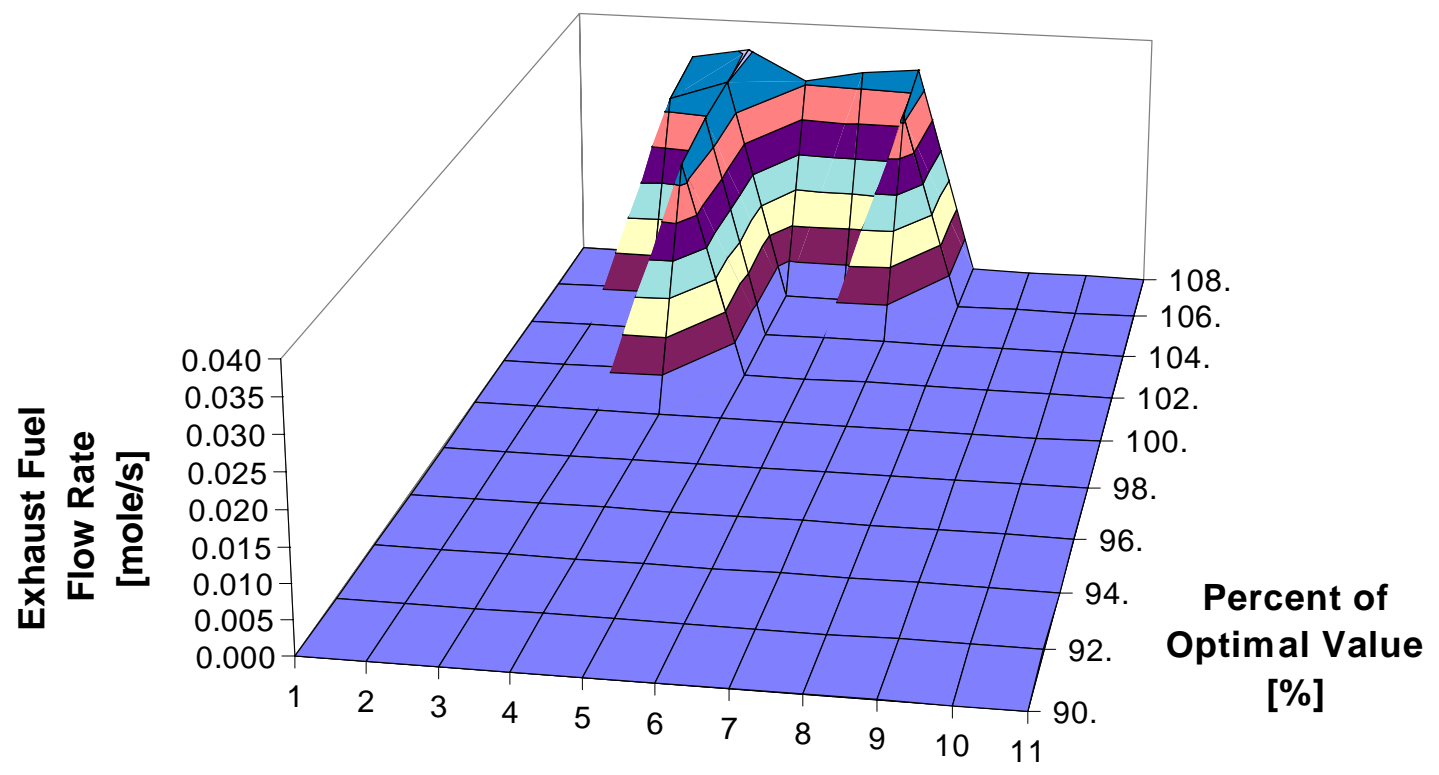

Air Port \# [1]

file: Sensitiv.xls

Figure 8. Air Injection Sensitivity 


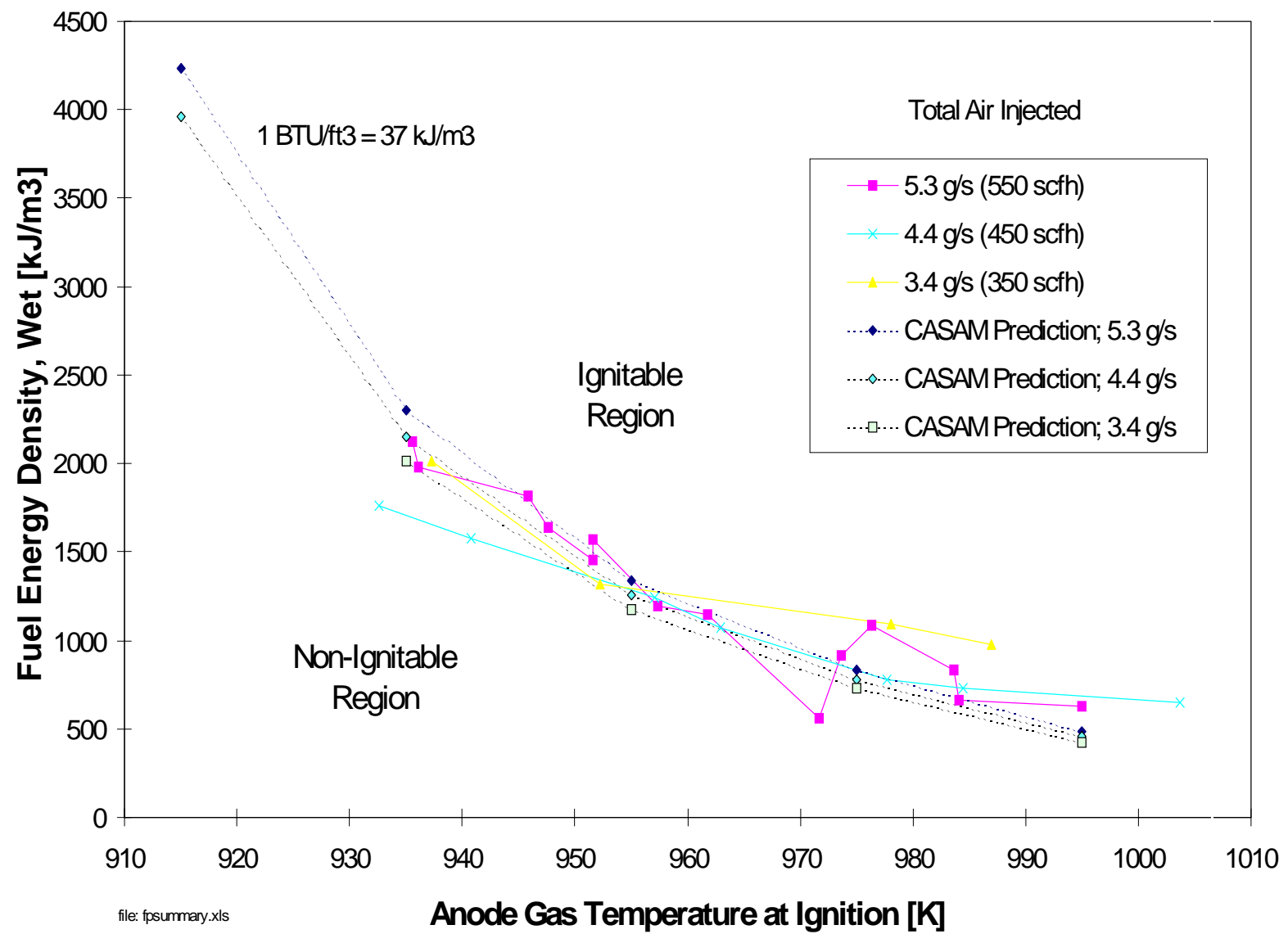

Figure 9. Experimental Ignition Data and Model Predictions 